\title{
Corrigendum to
}

\section{"Geochronological database and classification system for age uncertainties in Neotropical pollen records" published in Clim. Past, 12, 387-414, 2016}

\section{S. G. A. Flantua ${ }^{1}$, M. Blaauw ${ }^{2}$, and H. Hooghiemstra ${ }^{1}$}

${ }^{1}$ Research group of Palaeoecology and Landscape Ecology, Institute for Biodiversity and Ecosystem Dynamics (IBED), University of Amsterdam, Science Park 904, 1098 XH Amsterdam, the Netherlands

${ }^{2}$ School of Geography, Archaeology and Palaeoecology, Queen's University Belfast, Belfast, UK

Correspondence to: S. G. A. Flantua (s.g.a.flantua@uva.nl) and H. Hooghiemstra (h.hooghiemstra@uva.nl)

Published: 5 May 2017

The figshare link used in this paper (https://figshare.com/ $\mathrm{s} / 0 \mathrm{e} 9 \mathrm{afb} 8 \mathrm{fe} 758 \mathrm{a} 0 \mathrm{e} 6 \mathrm{e} 8 \mathrm{c} 8$ ) has become inactive. To access the supplementary information and corresponding database, please use: doi:10.6084/m9.figshare.2069722.v2. 